\title{
Part IV EMERGING CONTEXTS FOR DEVELOPMENT
}

As interest in teaching excellence grows, POD members find themselves called upon to assist in the training and support of academic professionals in a variety of roles. Here we report on three areas of practice that are relatively new in the field.

Nancy Chism shares here thoughts on facilitating TA training programs with an article probing the conditions for successful collaboration with departmental personnel responsible for TA supervision. Myra Wilhite and Anita Leininger report on a study of the practices used to promote faculty growth by chairs whose colleagues have identified them as excellent. The report provides a "profile" of the ideal supportive, reasonable chair. In the last piece, Len Ainsworth describes a participative approach to planning and developing management training programs for academic professionals. All three articles illustrate the benefits of supportive conversation and collaborative planning in effective professional development practice two central organizing principles and recurring themes in the history of the POD network. 